\title{
21-year retrospective study of the prevalence of Scopulariopsis brevicaulis in patients suspected of superficial mycoses
}

\author{
Anna B. Macura, Magdalena Skóra \\ Department of Mycology, Chair of Microbiology, Jagiellonian University Medical College, Krakow, Poland \\ Head of the Department: Paweł Krzyściak PhD
}

Postep Derm Alergol 2015; XXXII (3): 189-194 DOI: $10.5114 /$ pdia.2014.40965

\begin{abstract}
Introduction: In the genus Scopulariopsis, Scopulariopsis brevicaulis is the most common aetiological agent of infections in humans. It usually affects nails and is one of the commonest moulds associated with onychomycoses. Other forms of infections (skin, subcutaneous, deep tissues, and disseminated infections) have also been described. Aim: To examine the prevalence of $S$. brevicaulis in clinical materials obtained from patients suspected of keratinized tissues mycoses.

Material and methods: The analysis of the prevalence of S. brevicaulis in clinical specimens was based on mycological test's results carried out for patients who were referred with a suspicion of superficial mycoses to the Department of Mycology, Chair of Microbiology, Jagiellonian University Medical College from 1992 till 2012.

Results: In the years 1992-2012 16,815 clinical samples (nail scrapings, nail swabs, skin scrapings, skin swabs, hair) were collected. Pathogenic fungi were detected in 7193 samples and S. brevicaulis was present in 255 (3.5\%). The prevalence of $S$. brevicaulis in males and females was comparable. The species was most often isolated from toenails (80\%), both from males and females. In the analysed period we observed a decrease in the prevalence of S. brevicaulis. In most cases (60\%) S. brevicaulis occurred alone in $40 \%$ of S. brevicaulis positive cultures, other fungi were also isolated. The fungi most frequently isolated with $S$. brevicaulis were Trichophyton rubrum, T. mentagrophytes, Penicillium sp., Candida sp., and Aspergillus sp.

Conclusions: Scopulariopsis brevicaulis is not a common cause of superficial fungal infections of keratinized tissues, but is a typical mould associated with toenail onychomycosis. A proper identification of this species in onychomycoses is essential for the implementation of effective antifungal therapy.
\end{abstract}

Key words: Scopulariopsis brevicaulis, superficial mycoses, onychomycosis.

\section{Introduction}

Fungi from the genus Scopulariopsis occure in soil, air, organic waste, food, feed, plants, animals, and humans [1-6]. In humans they have been mainly associated with superficial infections of keratinized tissues, especially with onychomycoses [7-17]. They have also been described as a cause of cutaneous, subcutaneous, and deep tissues mycoses, e.g. endocarditis, pulmonary infection, bronchial infection, keratitis, endophthalmitis, sinusitis, otomycosis, meningitis, and disseminated infections [18-26]. These invasive infections are relatively rare but during the last two decades have been increasingly reported, particularly in immunocompromised patients.
In the genus Scopulariopsis, S. brevicaulis is the most common aetiological agent of infections in humans. Scopulariopsis brevicaulis is considered to be resistant to most antifungal drugs currently available, including amphotericin B and azole compounds [27-29]. The treatment of infections due to this species might be ineffective and invasive infections can directly threaten patient's life.

\section{Aim}

The aim of this study was to examine the prevalence of $S$. brevicaulis in clinical specimens obtained from patients suspected of superficial mycoses.

Address for correspondence: Magdalena Skóra PhD, Department of Mycology, Chair of Microbiology, Jagiellonian University Medical College, 18 Czysta St, 31-121 Krakow, Poland, phone: +48 1263308 77, e-mail: magdalena.skora@uj.edu.pl

Received: 5.06.2013, accepted: 2.01.2014. 


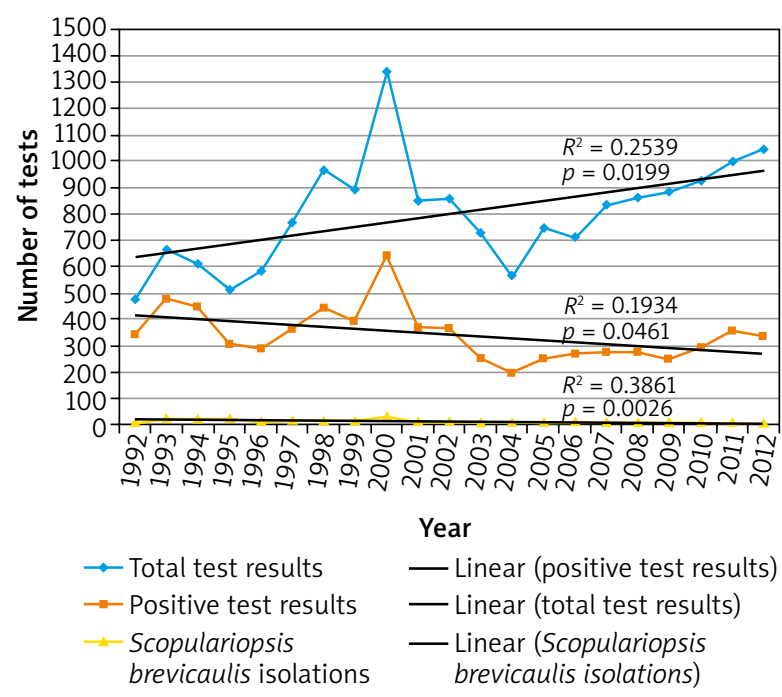

Figure 1. Number of test results obtained during the analysed period

\section{Material and methods}

The retrospective analysis of the mycological test results was performed.

Samples for mycological examination were collected from patients suspected of superficial mycoses who were referred to the Department of Mycology, Chair of Microbiology, Jagiellonian University Medical College from 1 January 1992 to 31 December 2012. The collected materials contained nail scrapings, nail swabs, skin scrapings, skin swabs, and hair.

The isolation and identification of the fungi were made in accordance with conventional mycological procedures.

\section{Statistical analysis}

The data were processed statistically using GRETL, version 1.9.11, and Statistica 10. The results were considered significant when $p \leq 0.05$.

\section{Results}

A total of 16,815 test results were analysed: 9600 from females and 7215 from males. Seven thousand one hundred and ninety-three (42.8\%) samples were positive for fungi, 3837 (40\%) in females and 3356 (46.5\%) in males. Out of 7193 fungi-positive specimens, 255 (3.5\%) yielded Scopulariopsis brevicaulis. The number of $S$. brevicaulis isolates was comparable in females and males - 125 (49\%) vs. 130 (51\%) isolates, respectively. The comparison of the mean prevalence of $S$. brevicaulis in positive materials in males and females yielded no statistically significant difference $(p=0.242106)$.

During the 21-year observation period the total number of mycological test results was increasing, while the number of positive test results and the number of S. brevicaulis isolates was decreasing (Figures 1 and 2). The trends were statistically significant $(p<0.05)$.

The prevalence of $S$. brevicaulis in various clinical materials is shown in Figure 3. The most common localization for this species was toenails ( $80 \%)$, both for females and males (respectively $80.8 \%$ and $79.2 \%$ of total S. brevicaulis isolates for each of the sex). The other localizations were as follows: fingernails (7\%), hand (6\%), foot $(5 \%)$, trunk (1\%), groin (1\%) for women, and foot ( $9 \%)$, fingernails ( $4 \%)$, hand $(2 \%)$, face $(2 \%)$, trunk $(2 \%)$, and groin (1\%) for men.

In the analysed period 10,470 nail samples were collected. Onychomycosis was diagnosed in 4806 (45.9\%) cases. Moulds were reported as an aetiological agent of

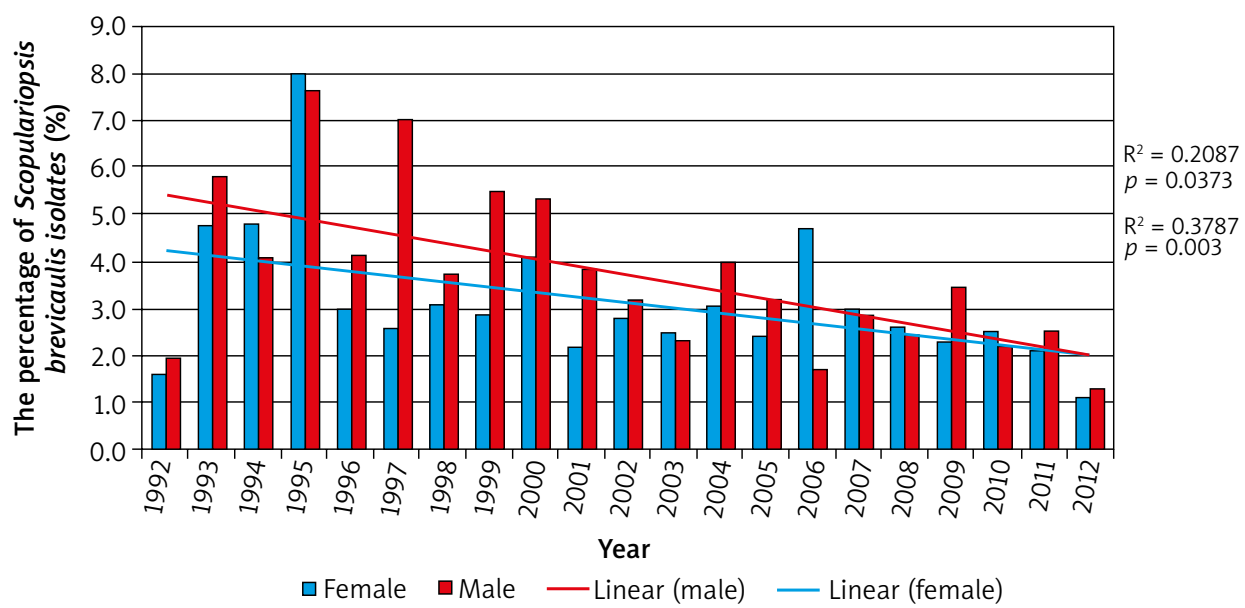

Figure 2. Percentage of Scopulariopsis brevicaulis isolates in fungi-positive specimens for each sex. The lines show a statistically significant $(p<0.05)$ decrease in the $S$. brevicaulis prevalence in fungi-positive specimens, both in females and males 
those infections in 1080 (22.5\%) cases and S. brevicaulis was identified in 218 - which comprised $4.5 \%$ of total onychomycoses and $22.5 \%$ of total mould-related onychomycoses. In the analysed period, the mean prevalence of S. brevicaulis in nail samples was $2.4 \%$. The percentage of $S$. brevicaulis isolates from nails in females and males was comparable - the mean prevalence for females was $2 \%$ and for males $2.9 \%$.

Scopulariopsis brevicaulis was mainly isolated from toenails (about $94 \%$ of nail isolates), occasionally from fingernails (about $6 \%$ of nail isolates). The prevalence of S. brevicaulis in toenails during the analysed period was 2.5\% (mean: $3.1 \%$ ), and the species was responsible for 5.5\% (mean: $5.7 \%$ ) of total toenail mycoses and $23.4 \%$ (mean: $28.3 \%$ ) of moulds-related toenail infections. The mean prevalence of S. brevicaulis in fungi-positive toenails samples was $5.6 \%$ in females and $5.8 \%$ in males, and the mean prevalence of this species in mould-related toenail mycoses was $24.2 \%$ and $32.9 \%$, respectively. In both cases the differences between the sexes were not statistically significant $(p=0.489039$ and $p=0.597148$, respectively). We noticed a decrease in the prevalence of S. brevicaulis in toenails, both in females and males, what was statistically significant ( $p<0.05)$ (Figure 4).

Scopulariopsis brevicaulis was isolated from 14 fingernail samples and the mean prevalence of the species in this clinical material was $0.6 \%$. There were no differences in the prevalence between the sexes $(0.6 \%$ and $0.5 \%$ in females and males, respectively). Scopulariopsis brevicaulis was an aetiological agent of $1.3 \%$ of total fingernail mycoses (mean: 1.5\%). The mean prevalence of $S$. brevicaulis in fingernail mycoses was comparable in females and males (1.2\% and $2 \%$, respectively; $p=$ $0.343876)$. In the analysed period, S. brevicaulis was identified as a cause of $6.8 \%$ of mould-related fingernail mycoses (mean: 11\%) - the mean prevalence of this species in females was $15.1 \%$ and in males $6.9 \%$, and the difference was not statistically significant $(p=0.164926)$.

Scopulariopsis brevicaulis was isolated predominantly as the sole aetiological agent. In $40.4 \%$ of cases also other fungi were cultured. Scopulariopsis brevicaulis coexisted both with dermatophytes, other moulds, and yeasts. The predominant coexisting species was Trichophyton rubrum. The list of fungi isolated together with S. brevicaulis is shown in Table 1.

\section{Discussion}

Scopulariopsis brevicaulis may cause various infections in humans - from superficial to life-threatening invasive mycoses. Superficial infections are usually caused by dermatophytes or yeasts, however, S. brevicaulis is one of the predominant species among nondermatophytic filamentous fungi in onychomycoses [7-15].
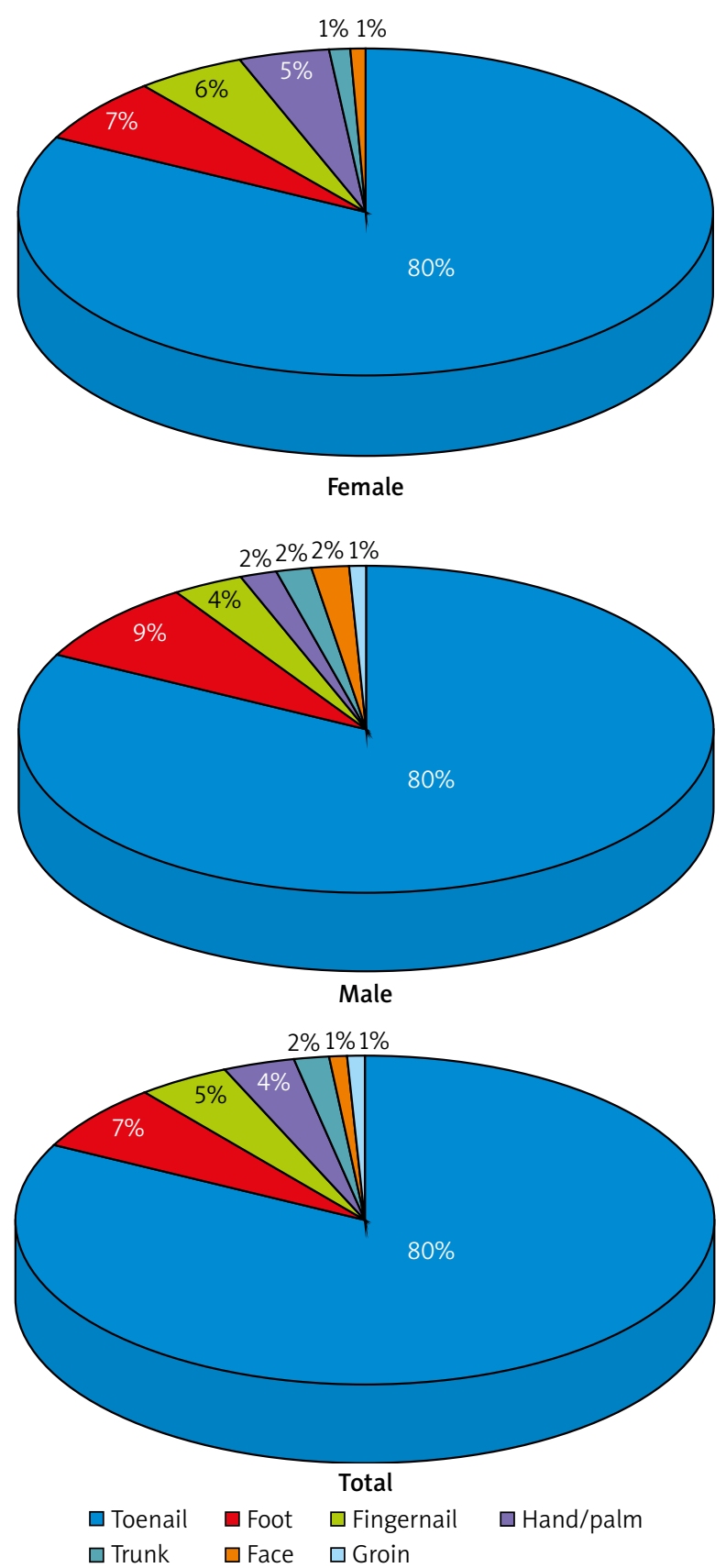

Figure 3. Prevalence of Scopulariopsis brevicaulis isolates in different clinical materials

Information about the prevalence of $S$. brevicaulis in superficial infections is sparse. Most of the information refers only to the occurrence of this species in onychomycoses, which are the most common clinical form of S. brevicaulis infections. We found only two retrospective analyses of the prevalence of $S$. brevicaulis in dermatomycosis. Petanović et al. investigated the presence of $S$. brevicaulis in nail, skin and scalp scrapings in the Croatian population [30]. Issakainen et al. performed 


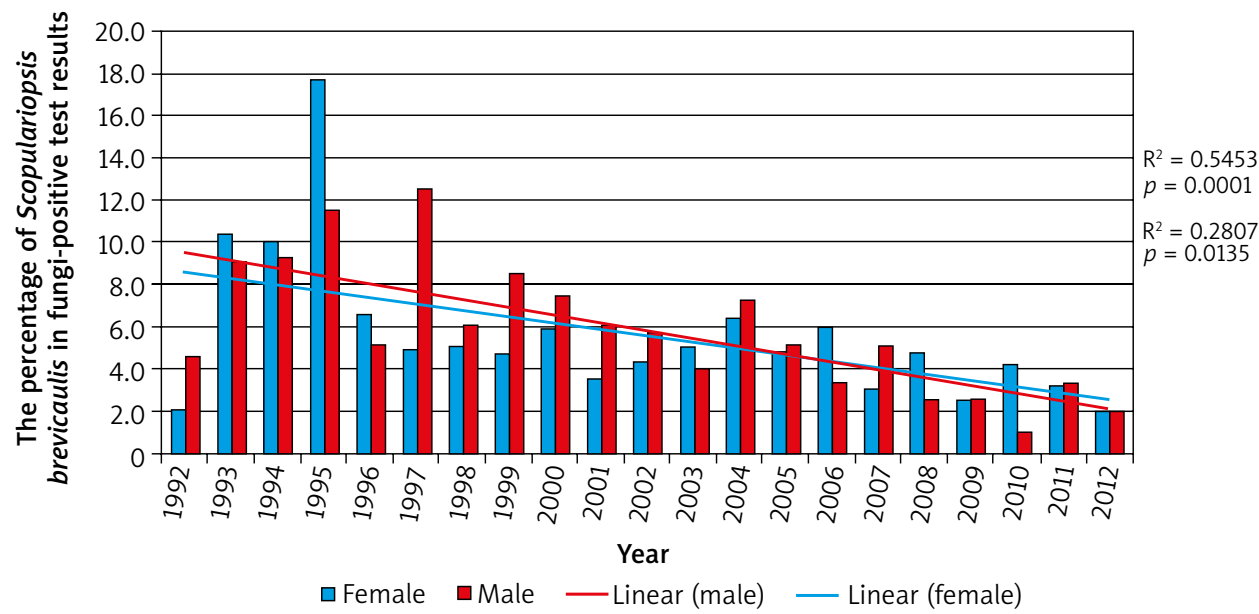

Figure 4. Percentage of Scopulariopsis brevicaulis in toenails. The lines show a statistically significant $(p<0.05)$ decrease in the $S$. brevicaulis prevalence in fungi-positive toenails samples, both in females and males

Table 1. Other fungi isolated with Scopulariopsis brevicaulis

\begin{tabular}{lcc}
\hline Group of fungi & $\begin{array}{c}\text { Genus/species } \\
\text { (number of isolates) }\end{array}$ & $\begin{array}{c}\text { Total number of isolates } \\
\text { (\% of S. brevicaulis positive samples) }\end{array}$ \\
\hline Dermatophytes & $\begin{array}{c}\text { Trichophyton rubrum (24) } \\
\text { Trichophyton mentagrophytes (17) } \\
\text { Epidermophyton floccosum (1) }\end{array}$ & 42 \\
& Penicillium sp. (22) & \\
\hline Moulds & Aspergillus sp. (11) & 44 \\
& Cephalosporium (3) & $(17.3 \%)$ \\
& Alternaria sp. (2) & \\
& Mucor sp. (2) & \\
& Trichoderma sp. (2) & \\
& Acremonium sp. (1) & \\
& Trichothecium roseum (1) & 26 \\
Yeasts & Candida sp. (20) & $(10.2 \%)$ \\
\end{tabular}

a multicentre study for Scopulariopsis and Scedosporium occurrence in nails and skin of Finnish patients [31].

In our study, S. brevicaulis was found in $3.5 \%$ of fungipositive clinical specimens collected from patients suspected of superficial mycoses. Onychomycoses related to $S$. brevicaulis yielded $4.5 \%$ of total fungal infections of nails and $22.5 \%$ of onychomycoses caused by moulds. Petanovic et al. isolated during 7 years isolated this species in 39 cases of dermatomycosis, what comprised $2.2 \%$ of mycologically positive samples [30]. Most isolates $(85.5 \%)$ in our study were cultured from nails, similarly to Issakainen et al., while Petanović et al. isolated S. brevicaulis mainly from skin - in total 39 isolates, 29 (74.4\%) were cultured from various skin localizations, only 10 (25.6\%) from nails [30, 31]. Jankowska-Konsur et al. in the 5-year survey of dermatomycoses in southwest Poland obtained similar results - S. brevicaulis was found in $2.5 \%$ of all fungi-positive clinical samples. It comprised $25.2 \%$ of all isolated moulds and was a cause of $4.2 \%$ of toenail onychomycoses [32]. The Korean group, who analysed 59 cases of onychomycosis due to nondermatophytic moulds during 10 years' period, found S. brevicaulis in 6 patients (10.2\%), only in toenails. That was the second most commonly isolated species, next to Aspergillus species [33]. In the study of onychomycoses carried out by Tosti et al., S. brevicaulis was isolated in 3.9\% of positive test results and in $28.8 \%$ of mould infections [13]. Other authors showed an even higher percentage of S. brevicaulis in mould-related onychomycoses. Mügge et al. and Bonifaz et al. found this species as an aetiological agent of nail infections caused by moulds in $42.8 \%$ and $43.5 \%$, respectively $[10,11]$.

There have been also reports which indicate that S. brevicaulis is rather rare cause of moulds-related onychomycoses. The Turkish investigators out of 33 cases of mould onychomycosis found only one (3\%) Scopulariopsis isolate [34]. As well Dhib et al. in the 22 years' retrospective study of onychomycoses in Tunisia yielded 
Scopulariopsis in a low percentage $-0.3 \%$ of fungi-positive nail samples [35]. The causative agents of onychomycoses were studied also by Bokhari et al. on Lahore (Pakistan) population and Gupta et al. on patients from Himachal Pradesh (India). They revealed the presence of S. brevicaulis in $2 \%$ and $2.1 \%$ of positive test results, respectively [36, 37]. Bassiri-Jahromi and Khaksar in the study of aetiological agents of fungal nail infections found S. brevicaulis to be a cause of $2.1 \%$ cases of whole nondermatophytic onychomycoses [9].

Scopulariopsis brevicaulis predominantly affects toenails, especially the big toe nail. It is rarely isolated from fingernails $[10,11,13,30,31]$. Our study confirms these data $-93.6 \%$ of nail isolates were cultured from toenails and $6.4 \%$ from fingernails.

Despite the fact that $S$. brevicaulis is not considered to be a typical skin pathogen, several case reports of skin infections due to this species have been reported. Scopulariopsis brevicaulis has been described as an aetiological agent of skin infections of: face [16, 17, 38, 39], lower limbs (including foot) [40, 41], and trunk [42]. Petanović et al. found this species in the following skin locations: limbs, head, trunk, and armpits [30]. In the study by Issakainen et al. Scopulariopsis was isolated from similar parts of the skin - feet, hands, upper body [31]. In our study, skin infections due to $S$. brevicaulis occurred sporadically. During a 21-year study we isolated from the skin only 37 (14.5\%) strains, mainly from the foot or hand/palm.

Scopulariopsis brevicaulis could be a primary pathogen or a co-pathogen of the skin and nails, but usually it has been reported as a secondary pathogen with dermatophytes [43]. The results of our study do not support these data. About $60 \%$ of S. brevicaulis isolates were identified as the sole aetiological agent of infection and only about $17 \%$ were cultured together with dermatophytes. Similarly in Issakainen et al.'s study, 30\% of cases of Scopulariopsis isolations were associated with dermatophytes [31].

The pathogenicity of S. brevicaulis in superficial mycoses is unclear and still disputable. Keratin degradation which determines the ability of fungi to cause skin and nail mycoses does not appear to be species specific in S. brevicaulis. Some S. brevicaulis strains are keratinolytic while others are not [44]. Isolation and identification of S. brevicaulis in nail and skin samples is not equivocal to infection. As other saprotrophic fungi, S. brevicaulis could be only the colonizer of the skin and nails, or a contaminant of a clinical material or culture. Therefore, to make a proper diagnosis, the clinical picture of the lesion and mycological test result should be considered. The isolation of S. brevicaulis from clinical materials collected from skin or nails, as well as other moulds, should be repeated in consecutive cultures from additional samples. In the mixed cultures, particular attention should be paid to the presence of other pathogenic fungi, especially dermatophytes, which are an undisputed cause of superfi- cial mycoses. In simultaneous isolation of S. brevicaulis and dermatophytes, S. brevicaulis is usually considered as a secondary invader.

\section{Conclusions}

Scopulariopsis brevicaulis is not a common cause of superficial fungal infections of keratinized tissues, but is a typical mould associated with toenail onychomycosis. A proper diagnosis of a causative agent of mycosis is essential to implement appropriate treatment. In the case of $S$. brevicaulis infection, this is of particular importance, because the species has been reported to be resistant in vitro to broad-spectrum antifungal agents available today and responds more poorly to a variety of treatment methods than dermatophytes [27-29].

\section{Acknowledgments}

We would like to thank Mrs Kinga Przewoźniak, M.Sc. for statistical processing of the data.

The study was financed by the National Science Centre (grant number: N N401 548140).

The results, Figure 1, Figure 2, Figure 4, and Table 1 with some modifications were included in Magdalena Skóra's doctoral thesis (Skóra M. In vitro evaluation of factors influencing the pathogenicity of fungi of the genus Scopulariopsis. Jagiellonian University Medical College, Krakow, 2013).

\section{Conflict of interest}

The authors declare no conflict of interest.

\section{References}

1. Ropars J, Cruaud C, Lacoste S, Dupont J. A taxonomic and ecological overview of cheese fungi. Int J Food Microbiol 2012; 155: 199-210.

2. Chen AJ, Huang LF, Wang LZ, et al. Occurrence of toxigenic fungi in ochratoxin A contaminated liquorice root. Food Addit Contam Part A Chem Anal Control Expo Risk Assess 2011; 28: 1091-7.

3. Plewa K, Lone E. Seasonal biodiversity of pathogenic fungi in farming air area. Case study. Wiad Parazytol 2011; 57: 118-22.

4. Rota A, Calicchio E, Nardoni S, et al. Presence and distribution of fungi and bacteria in the reproductive tract of healthy stallions. Theriogenology 2011; 76: 464-70.

5. Awad MF, Kraume M. Mycological survey of activated sludge in MBRs. Mycoses 2011; 54: e493-8.

6. Roigé MB, Aranguren SM, Riccio MB, et al. Mycobiota and mycotoxins in fermented feed, wheat grains and corn grains in Southeastern Buenos Aires Province, Argentina. Rev Iberoam Micol 2009; 26: 233-7.

7. Lee MH, Hwang SM, Suh MK, et al. Onychomycosis caused by Scopulariopsis brevicaulis: report of two cases. Ann Dermatol 2012; 24: 209-13.

8. Moreno G, Arenas R. Other fungi causing onychomycosis. Clin Dermatol 2010; 28: 160-3.

9. Bassiri-Jahromi S, Khaksar AA. Nondermatophytic moulds as a causative agent of onychomycosis in Tehran. Indian J Dermatol 2010; 55: 140-3. 
10. Bonifaz A, Cruz-Aguilar P, Ponce RM. Onychomycosis by molds. Report of 78 cases. Eur I Dermatol 2007; 17: 70-2.

11. Mügge C, Haustein UF, Nenoff P. Causative agents of onychomycosis - a retrospective study. J Dtsch Dermatol Ges 2006; 4: 218-28.

12. Boukachabine K, Agoumi A. Onychomycosis in Morocco: experience of the parasitology and medical mycology laboratory from Rabat children hospital (1982-2003). Ann Biol Clin 2005; 63: 639-42.

13. Tosti A, Piraccini BM, Lorenzi S. Onychomycosis caused by nondermatophytic molds: clinical features and response to treatment of 59 cases. J Am Acad Dermatol 2000; 42: 217-24.

14. García-Martos P, Domínguez I, Marín P, et al. Onychomycoses caused by non-dermatophytic filamentous fungi in Cádiz. Enferm Infecc Microbiol Clin 2000; 18: 319-24.

15. López-Jodra O, Torres-Rodríguez JM. Unusual fungal species causing onychomycosis. Rev Iberoam Micol 1999; 16: S11-5.

16. Chung WK, Sung H, Kim MN, et al. Treatment-resistant Scopulariopsis brevicaulis infection after filler injection. Acta Derm Venereol 2009; 89: 636-8.

17. Wu CY, Lee CH, Lin HL, Wu CS. Cutaneous granulomatous infection caused by Scopulariopsis brevicaulis. Acta Derm Venereol 2009; 89: 103-4.

18. Jain D, Oberoi JK, Shahi SK, et al. Scopulariopsis brevicaulis infection of prosthetic valve resembling aspergilloma on histopathology. Cardiovasc Pathol 2011; 20: 381-3.

19. Satyavani M, Viswanathan R, Harun NS, Mathew L. Pulmonary Scopulariopsis in a chronic tobacco smoker. Singapore Med J 2010; 51: e137-9.

20. Yang Q, Wei J, Chen Z. Fatal bronchial invasion of Scopulariopsis brevicaulis in an acute monocytic leukemia patient. Diagn Microbiol Infect Dis 2012; 73: 369-71.

21. Bunya VY, Hammersmith KM, Rapuano CJ, et al. Topical and oral voriconazole in the treatment of fungal keratitis. Am J Ophthalmol 2007; 143: 151-3.

22. Aydin S, Ertugrul B, Gultekin B, et al. Treatment of two postoperative endophthalmitis cases due to Aspergillus flavus and Scopulariopsis spp. with local and systemic antifungal therapy. BMC Infect Dis 2007; 7: 87.

23. Beltrame A, Sarmati L, Cudillo L, et al. A fatal case of invasive fungal sinusitis by Scopulariopsis acremonium in a bone marrow transplant recipient. Int I Infect Dis 2009; 13: e488-92.

24. Besbes M, Makni F, Cheikh-Rouhou F, et al. Otomycosis due to Scopulariopsis brevicaulis. Rev Laryngol Otol Rhinol (Bord) 2002; 123: 77-8.

25. Nwabuisi C, Salami AK, Abdullahi NA, Agbede OO. Scopulariopsis associated meningitis in adult Nigerian AIDS patient - a case report. West Afr J Med 2003; 22: 364-5.

26. Vignon M, Michonneau D, Baixench MT, et al. Disseminated Scopulariopsis brevicaulis infection in an allogeneic stem cell recipient. Bone Marrow Transplant 2011; 46: 1276-7.

27. Carrillo-Muńoz AJ, Cárdenes CD, Carrillo-Orive B, et al. In vitro antifungal activity of voriconazole against dermatophytes and superficial isolates of Scopulariopsis brevicaulis. Rev Iberoam Micol 2005; 22: 110-3.

28. Cuenca-Estrella M, Gomez-Lopez A, Buitrago MJ, et al. In vitro activities of 10 combinations of antifungal agents against the multiresistant pathogen Scopulariopsis brevicaulis. Antimicrob Agents Chemother 2006; 50: 2248-50.

29. Skóra M, Macura AB, Bulanda M. In vitro antifungal susceptibility of Scopulariopsis brevicaulis isolates. Med Mycol 2014; 52: 723-7.
30. Petanović M, Tomić Paradzik M, Kristof Z, et al. Scopulariopsis brevicaulis as the cause of dermatomycosis. Acta Dermatovenerol Croat 2010; 18: 8-13.

31. Issakainen J, Heikkilä H, Vainio E, et al. Occurrence of Scopulariopsis and Scedosporium in nails and keratinous skin. A 5-year retrospective multi-center study. Med Mycol 2007; 45: 201-9.

32. Jankowska-Konsur A, Dyląg M, Hryncewicz-Gwóźdź A, et al. A 5-year survey of dermatomycoses in southwest Poland, years 2003-2007. Mycoses 2011; 54: 162-7.

33. Hwang SM, Suh MK, Ha GY. Onychomycosis due to nondermatophytic molds. Ann Dermatol 2012; 24: 175-80.

34. Hilmioğlu-Polat S, Metin DY, Inci R, et al. Non-dermatophytic molds as agents of onychomycosis in Izmir, Turkey - a prospective study. Mycopathologia 2005; 160: 125-8.

35. Dhib I, Fathallah A, Yaacoub A, et al. Clinical and mycological features of onychomycosis in central Tunisia: a 22 years retrospective study (1986-2007). Mycoses 2013; 56: 273-80.

36. Bokhari MA, Hussain I, Jahangir M, et al. Onychomycosis in Lahore, Pakistan. Int J Dermatol 1999; 38: 591-5.

37. Gupta M, Sharma NL, Kanga AK, et al. Onychomycosis: clinico-mycologic study of 130 patients from Himachal Pradesh, India. Indian I Dermatol Venereol Leprol 2007; 73: 389-92.

38. Oh BJ, Chae MJ, Cho D, et al. Infection with Scopulariopsis brevicaulis after cosmetic surgery of the face. Korean J Lab Med 2006; 26: 32-5.

39. Bruynzeel I, Starink TM. Granulomatous skin infection caused by Scopulariopsis brevicaulis. I Am Acad Dermatol 1998; 39: 365-7.

40. Anandan V, Nayak V, Sundaram S, Srikanth P. An association of Alternaria alternata and Scopulariopsis brevicaulis in cutaneous phaeohyphomycosis. Indian I Dermatol Venereol Leprol 2008; 74: 244-7.

41. Ginarte M, Pereiro M Jr, Fernández-Redondo V, Toribio J. Plantar infection by Scopulariopsis brevicaulis. Dermatology 1996; 193: 149-51.

42. Dhar J, Carey PB. Scopulariopsis brevicaulis skin lesions in an AIDS patient. AIDS 1993; 7: 1283-4.

43. Stefanato CM, Verdolini R. Histopathologic evidence of the nondermatophytic mould Scopulariopsis brevicaulis masking the presence of dermatophytes in a toenail infection. J Cutan Pathol 2009; 36: 8-12.

44. Filipello Marchisio V, Fusconi A, Querio FL. Scopulariopsis brevicaulis: a keratinophilic or a keratinolytic fungus? Mycoses 2000; 43: 281-92. 